\title{
Analysis of Key Elements of Emergency Response Ability of Hazardous Chemicals Based on AHP Method
}

\author{
Fengfeng Yang ${ }^{1,}{ }^{*}, \mathrm{Ke} \mathrm{Gai}^{1}$, Feng Cao ${ }^{1}$, Rili Yang ${ }^{1}$, Jufeng Zhang ${ }^{1}$,Siyang Wang ${ }^{1}$, Ruiqing Su $^{1}$, Liping Bai $^{2}$, Lan Y $^{1}$ \\ ${ }^{1}$ School of Energy Engineering, LongDong University, 745000, China \\ ${ }^{2}$ Gansu Energy Qingyang Coal and Electricity Corporation Ltd., 745000, China
}

\begin{abstract}
A evaluation system was constructed and each weight of the indexes was calculated based on the principle of AHP (Analytic Hierarchy Process), which were benefit of safety and sustainable development of chemical enterprise, emergency response capacity, accidents numbers and property losses The results show that emergency prevention capability and emergency preparedness capability are the key elements in the first-level indicator system. The plan initiation, drill, hazard source control and monitoring and early warning, emergency command, coordination and rapid response capability are the key elements in the secondary indicators.
\end{abstract}

\section{Introductions}

With the rapid development of our country's economy and society, chemical accidents happen constantly, and the situation of safe production is very serious. For example, Tianjiayi's "3 -21 "explosion caused 78 deaths and 566 injuries. Jiangsu Shurangama Chemical Company's "4 16 " deflagration accident killed 8 people and injured 9 people. There are many enterprises in the chemical industry park, and the dangerous chemicals produced, stored and transported are of great risk, variety and quantity. Once a chemical accident occurs, it may not be dealt with timely and effectively due to insufficient emergency response capacity, resulting in serious accident consequences ${ }^{[1]}$.

In recent years, chemical safety production has become the focus of national attention. The number of accidents has increased and the damage has increased. It is particularly necessary to evaluate and construct the emergency response capability of hazardous chemicals enterprises.

Yang Jixing ${ }^{[2]}$ constructed an evaluation system of five first-level indicators and 23 second-level indicators, including risk identification and control, prevention and preparation, disposal and rescue, postrecovery and reconstruction, and emergency response capacity guarantee. Yang zhenhong ${ }^{[3]}$ established an evaluation system of 4 first-level indicators, 9 secondlevel indicators and 31 third-level indicators. Chen Wenta ${ }^{[4]}$ evaluated the triangle rescue mathematics theory and the fuzzy comprehensive evaluation team's emergency rescue capability. Zhang Shaogang ${ }^{[5]}$ estab lished a three-level emergency capability evaluation model and applied it with AHP-fuzzy comprehensive method. Based on the emergency management process, this paper analyses the key elements of the emergency capability improvement process by establishing the index system that affects the emergency capability of hazardous chemicals enterprises, and promotes the emergency response capability of hazardous chemicals accidents.

\section{Emergency capability evaluation model for hazardous chemicals accidents}

According to the various factors affecting emergency response capability, the AHP method is used to establish a multi-level structure index system, and the emergency response capability is quantitatively studied to find out the key elements in the emergency capability improvement process to achieve the purpose of optimization decision-making.

Table 1 Hierarchical model of emergency management capability evaluation of hazardous chemicals enterprises

\begin{tabular}{|c|c|c|}
\hline $\begin{array}{l}\text { Target } \\
\text { layer }\end{array}$ & Criteria layer & Indicator layer \\
\hline \multirow{11}{*}{$\begin{array}{r}\text { Emergency } \\
\text { apability } \\
\text { evaluation }\end{array}$} & \multirow{4}{*}{$\begin{array}{c}\text { Emergency } \\
\text { prevention } \\
\text { capability }\left(B_{I}\right)\end{array}$} & Monitoring and warning $\left(C_{l}\right)$ \\
\hline & & Hazard control $\left(C_{2}\right)$ \\
\hline & & Disaster insurance $\left(C_{3}\right)$ \\
\hline & & Management ability $\left(C_{4}\right)$ \\
\hline & \multirow{4}{*}{$\begin{array}{l}\text { Emergency } \\
\text { preparedness } \\
\quad\left(B_{2}\right)\end{array}$} & Perfection of system $\left(C_{5}\right)$ \\
\hline & & $\begin{array}{c}\text { Emergency resource } \\
\text { protection }\left(C_{6}\right)\end{array}$ \\
\hline & & Emergency team $\left(C_{7}\right)$ \\
\hline & & Preplan rehearsal $\left(C_{8}\right)$ \\
\hline & \multirow{3}{*}{$\begin{array}{c}\text { Emergency } \\
\text { response } \\
\text { capability } \\
\left(B_{3}\right) \\
\end{array}$} & Plan start $\left(C_{9}\right)$ \\
\hline & & $\begin{array}{l}\text { Rapid response capability } \\
\left(C_{10}\right)\end{array}$ \\
\hline & & Emergency experts and \\
\hline
\end{tabular}

\footnotetext{
* Corresponding author: Fengfeng Yang, 2356059065@qq.com
} 


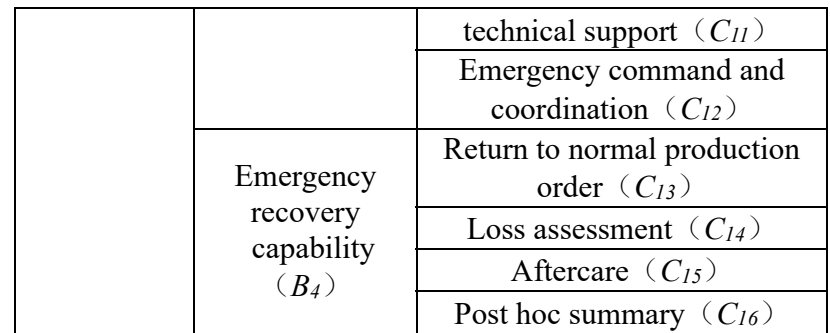

According to the principle and analysis process of AHP, the emergency capability evaluation is taken as the target layer, and the prevention, preparation, response and recovery in the emergency management process are taken as the criterion layer, and the index layer composed of 16 secondary indicators is determined. The final evaluation model of emergency management capability of hazardous enterprises is shown in Table 1.

\section{Weight calculations of evaluation indexes}

\subsection{Determination of judgment criteria}

As a systematic evaluation method, the AHP method must be evaluated by language description based on the unified comparison benchmark in the element pairing comparison. Through experiments, Satty ${ }^{[6]}$ found that the scale of Numbers 1-9 reflected the judgment ability of the majority, so the scale of 1-9 was adopted and the specific detail was shown in table 2.

Table 2 Meaning of 1-9 scale

\begin{tabular}{|c|c|}
\hline Scaling & Meaning \\
\hline 1 & $C_{i}$ has the same effect as $C_{j}$ \\
\hline 3 & $C_{i}$ is slightly more influential than $C_{j}$ \\
\hline 5 & $C_{i}$ has a stronger influence than $C_{j}$ \\
\hline 7 & $C_{i}$ is significantly stronger than $C_{j}$ \\
\hline 9 & $C_{i}$ is definitely stronger than $C_{j}$ \\
\hline $\begin{array}{c}2 、 4 、 6 、 \\
8\end{array}$ & $\begin{array}{c}\text { The intermediate value of the above two } \\
\text { adjacent judgment levels }\end{array}$ \\
\hline $\begin{array}{c}1,1 / 2, \cdots \\
, 1 / 9\end{array}$ & $\begin{array}{c}\text { The factors } i \text { and } j \text { are compared as } C_{i j}, \\
\text { then the factor } j \text { is compared with } i,\end{array}$ \\
$C_{i j}=1 / \mathrm{C}_{j i}$
\end{tabular}

\subsection{Construct a pairwise judgment matrix}

According to the calculation principle of the analytic hierarchy process, the importance relationship between each element is determined, and the judgment matrix is constructed by using the 1-9 scale method. According to the score results, the comparison results of the relative importance of each indicator are shown in Table 3.

Table 3 Comparison of the importance of emergency prevention capabilities

\begin{tabular}{|c|c|c|c|c|c|}
\hline$B_{1}$ & $C_{1}$ & $C_{2}$ & $C_{3}$ & $C_{4}$ & $W_{A i}$ \\
\hline$C_{I}$ & 1 & $1 / 2$ & 3 & 2 & 0.29 \\
\hline$C_{2}$ & 2 & 1 & 3 & 2 & 0.41 \\
\hline$C_{3}$ & $1 / 3$ & $1 / 3$ & 1 & $1 / 2$ & 0.11 \\
\hline
\end{tabular}

\begin{tabular}{|l|l|l|l|l|l|}
\hline$C_{4}$ & $1 / 2$ & $1 / 3$ & 2 & 1 & 0.19 \\
\hline
\end{tabular}

Table 4 Comparison of the importance of emergency preparedness

\begin{tabular}{|c|c|c|c|c|c|}
\hline$B_{2}$ & $C_{5}$ & $C_{6}$ & $C_{7}$ & $C_{8}$ & $W_{A i}$ \\
\hline$C_{5}$ & 1 & 2 & 2 & $1 / 2$ & 0.26 \\
\hline$C_{6}$ & $1 / 2$ & 1 & 3 & $1 / 2$ & 0.21 \\
\hline$C_{7}$ & $1 / 2$ & $1 / 3$ & 1 & $1 / 3$ & 0.11 \\
\hline$C_{8}$ & 2 & 2 & 3 & 1 & 0.42 \\
\hline
\end{tabular}

Table 5 Comparison of the importance of emergency response capabilities

\begin{tabular}{|c|c|c|c|c|c|}
\hline $\boldsymbol{B}_{3}$ & $C_{9}$ & $C_{10}$ & $C_{11}$ & $C_{12}$ & $W_{A i}$ \\
\hline$C_{9}$ & 1 & 2 & 3 & 2 & 0.4 \\
\hline$C_{10}$ & $1 / 2$ & 1 & 2 & $1 / 3$ & 0.17 \\
\hline$C_{11}$ & $1 / 3$ & $1 / 2$ & 1 & $1 / 3$ & 0.11 \\
\hline$C_{12}$ & $1 / 2$ & 3 & 3 & 1 & 0.32 \\
\hline
\end{tabular}

Table 6 Comparison of the importance of emergency recovery capabilities

\begin{tabular}{|c|c|c|c|c|c|}
\hline$B_{4}$ & $C_{13}$ & $C_{14}$ & $C_{15}$ & $C_{16}$ & $W_{A i}$ \\
\hline$C_{13}$ & 1 & 2 & $1 / 3$ & 2 & 0.24 \\
\hline$C_{14}$ & $1 / 2$ & 1 & $1 / 2$ & 2 & 0.19 \\
\hline$C_{15}$ & 3 & 2 & 1 & 3 & 0.46 \\
\hline$C_{16}$ & $1 / 2$ & $1 / 2$ & $1 / 3$ & 1 & 0.11 \\
\hline
\end{tabular}

Table 7 Comparison of the importance of emergency management capabilities of hazardous chemicals enterprises

\begin{tabular}{|c|c|c|c|c|c|}
\hline$A$ & $B_{1}$ & $B_{2}$ & $B_{3}$ & $B_{4}$ & $W_{A i}$ \\
\hline$B_{1}$ & 1 & 2 & $1 / 2$ & 2 & 0.27 \\
\hline$B_{2}$ & $1 / 2$ & 1 & $1 / 2$ & 2 & 0.19 \\
\hline$B_{3}$ & 2 & 2 & 1 & 3 & 0.42 \\
\hline$B_{4}$ & $1 / 2$ & $1 / 2$ & $1 / 3$ & 1 & 0.12 \\
\hline
\end{tabular}

\subsection{Consensus test of the criterion layer}

According to the judgment matrix relationship and the calculated weight vector, the consistency test is performed, and the test results are shown in Table 8.

Table 8 Consistency test results

\begin{tabular}{|c|c|c|c|c|}
\hline Indicator layer & $\lambda_{\max }$ & $C I$ & $R I$ & $C R$ \\
\hline$A-B$ & 4.08 & 0.03 & 0.9 & 0.03 \\
\hline$B_{1}-C_{1-4}$ & 4.14 & 0.05 & 0.9 & 0.06 \\
\hline$B_{2}-C_{5-8}$ & 4.14 & 0.05 & 0.9 & 0.06 \\
\hline$B_{3}-C_{9-12}$ & 4.15 & 0.05 & 0.9 & 0.06 \\
\hline$B_{4}-C_{13-16}$ & 4.08 & 0.03 & 0.9 & 0.03 \\
\hline
\end{tabular}

As can be seen from Table 8 , all judgment matrices $\mathrm{CR}<0.1$, all meeted the conformance test criteria.

\subsection{Hierarchical total ordering}

The above is the weight vector of a group of elements to an element in the previous layer. Total ranking is the ranking weight of the relative importance of all factors in the same level to the target level. The overall ranking of all factors of emergency response capacity 
of hazardous chemical enterprises was conducted, and the results are shown in 9 .

Table 9 Level total ordering and each indicator weight result

\begin{tabular}{|c|c|c|c|c|}
\hline $\begin{array}{l}\text { Criterion } \\
\text { layer } \\
\text { indicators }\end{array}$ & $\begin{array}{l}\text { Index } \\
\text { layer } \\
\text { index }\end{array}$ & $\begin{array}{c}\text { Index } \\
\text { layer } \\
\text { weight }\end{array}$ & $\begin{array}{l}\text { The } \\
\text { sorting }\end{array}$ & $\begin{array}{c}\text { Criterion } \\
\text { layer } \\
\text { weight }\end{array}$ \\
\hline \multirow{4}{*}{$\begin{array}{c}\text { Emergency } \\
\text { prevention } \\
\text { capability } \\
\left(B_{1}\right)\end{array}$} & $C_{l}$ & 0.0783 & 5 & \multirow{4}{*}{0.27} \\
\hline & $C_{2}$ & 0.1107 & 3 & \\
\hline & $C_{3}$ & 0.0297 & 12 & \\
\hline & $C_{4}$ & 0.0513 & 8 & \\
\hline \multirow{4}{*}{$\begin{array}{c}\text { Emergency } \\
\text { preparednes } \\
\mathrm{s}\left(B_{2}\right)\end{array}$} & $C_{5}$ & 0.0494 & 9 & \multirow{4}{*}{0.19} \\
\hline & $C_{6}$ & 0.0399 & 11 & \\
\hline & $C_{7}$ & 0.0209 & 15 & \\
\hline & $C_{8}$ & 0.0798 & 4 & \\
\hline \multirow{4}{*}{$\begin{array}{c}\text { Emergency } \\
\text { response } \\
\text { capability } \\
\quad\left(B_{3}\right)\end{array}$} & C 9 & 0.1680 & 1 & \multirow{4}{*}{0.42} \\
\hline & $C_{10}$ & 0.0714 & 6 & \\
\hline & $C_{11}$ & 0.0462 & 10 & \\
\hline & $C_{12}$ & 0.1344 & 2 & \\
\hline \multirow{4}{*}{$\begin{array}{c}\text { Emergency } \\
\text { recovery } \\
\text { capability } \\
\left(B_{4}\right)\end{array}$} & $C_{13}$ & 0.0288 & 13 & \multirow{4}{*}{0.12} \\
\hline & $C_{14}$ & 0.0228 & 14 & \\
\hline & $C_{15}$ & 0.0552 & 7 & \\
\hline & $C_{16}$ & 0.0132 & 16 & \\
\hline
\end{tabular}

\subsection{Level total order consistency test}

Index of overall ranking of hierarchical structure relative to hierarchical structure consistency:

$$
C I_{G}=\sum_{i=1}^{\mathrm{m}} a_{i} C I_{i}=0.27 \times 0.03+0.19 \times 0.06+0.42 \times 0.06
$$$$
+0.12 \times 0.03=0.0483
$$

The total average random consistency index of the total ranking of the hierarchical structure relative to the hierarchical structure:

$$
\begin{array}{r}
R I_{G}=\sum_{i=1}^{m} a_{i} R I_{i}=0.27 \times 0.9+0.19 \times 0.9+ \\
0.42 \times 0.9+0.12 \times 0.9=0.988
\end{array}
$$

Index of overall relative consistency of hierarchical structure:

$$
C R_{G}=\frac{C I_{G}}{R I_{G}}=\frac{0.0483}{0.988}=0.0489
$$

The results of the hierarchical sorting consistency check are shown in Table 10.

Table 10 Total ranking consistency test results

\begin{tabular}{|c|c|c|c|}
\hline Indicator layer & $C I_{G}$ & $R I_{G}$ & $C R_{G}$ \\
\hline$A$ & 0.0483 & 0.988 & 0.0489 \\
\hline
\end{tabular}

It can be seen from Table 10 that $C R_{G}<0.1$, it shows that the judgment matrix of the indicator system passes the consistency test.

\section{Results analysis}

According to the above weight calculation results and overall hierarchical ranking results, it can be seen that the index weight of the criterion layer for the evaluation of emergency response capability of hazardous chemical enterprises is ranked from the largest to the smallest in order of emergency response capability (0.42), emergency prevention capability $(0.27)$, emergency preparation capability $(0.19)$ and emergency recovery capability $(0.12)$. Therefore, in the emergency management process, hazardous chemicals enterprises should focus on strengthening the emergency response capability and emergency prevention capability of hazardous chemicals enterprises.

According to the weight results of each index, the indicators such as pre-plan initiation (0.1680), emergency command and coordination (0.1344), hazard source control $(0.1107)$, monitoring and early warning (0.0783), pre-plan exercise (0.0798) and emergency quick response capability (0.0714) account for a larger weight. The ability of emergency team construction, post-event summary and evaluation is very low, which needs to be paid attention to in the process of emergency management capacity construction of hazardous chemical enterprises.

\section{Conclusions}

The emergency response evaluation system of chemical enterprises was constructed, including four first-level indicators and 16 second-level indicators, and the two-two judgment matrix was constructed to obtain the weight of each indicator. All indicators and the overall ranking passed the consistency test. It is considered that emergency prevention and response capability are the key elements of first-level indicators, and emergency quick response capability, emergency command and coordination, plan initiation, hazard source control, monitoring and early warning and plan exercise are the key elements of second-level indicators.

\section{Acknowledgement}

This work was financially supported by china science industry-university-research innovation consortium project (ZLGC201902), youth science and technology innovation project of Long Dong college (XYZK1702), science and technology research project(MTKJ2018-277,MTKJ 2018-279), youth fund of Gansu province (18JR3RM240), and research projects of safety production in Gansu province (GAJ00004,GAJ00011).

\section{References}

1. Feiyue Wang, Wei Wang. Research on evaluation of emergency management capability for chemical industrial park[J].Journal of Safety Science and Technology, 2017, 13(06):132-138. 
2. Jixing Yang. Application of fuzzy mathematics evaluation method in emergency capacity evaluation of chemical industrial parks [J].Safety \& Security, 2013, 34(08):37-39.

3. Zhenhong Yang, Penggang Tian, et al. Assessment on emergency management capability of chemical industrial park based on extension theory [J]. Journal of Safety Science and Technology, 2016, 12(08): 104-108

4. Wentao Chen, Shiyou Ge. Capability evaluation on emergency response ability for accidents in chemical industry parks based on triangular fuzzy number [J]. Journal of Catastrophology, 2015, 30(02):167-171.

5. Shaogang Zhang, Mei Zhao, Xiaomin Ni, et al. On the comprehensive emergency probability of chemical industry park based on the AHP-fuzzy evaluation method [J]. Journal of Safety and Environment,2015,15(01):77-83

6. Saaty T.L. The analytic hierarchy process $[\mathrm{M}]$. McGraw-Hill, NewYork, 1980 